\title{
"YO HE VISTO UN PÁJARO VERDE": EXPERIENCIA, MEMORIA Y AUTOFICCIÓN FANTÁSTICA EN LA OBRA VANGUARDISTA DE JUAN EMAR
}

\section{"I HAVE SEEN A GREEN BIRD": EXPERIENCE, MEMORY AND FANTASTIC SELF-FICTION IN THE AVANT-GARDE WORKS OF JUAN EMAR}

\author{
Cecilia Rubio Rubio \\ Universidad de Concepción, Chile \\ crubio@udec.cl
}

\begin{abstract}
Resumen:
En este artículo propongo que el relato "El pájaro verde" de Juan Emar toma la forma de una autoficción fantástica, de acuerdo con los planteamientos teóricos sobre la autoficción de Vincent Colonna. Propongo también que en este relato la forma autoficcional adquiere su carácter vanguardista al ser puesto en correlación con una metadiscursividad propia de la modernidad narrativa, correlación que puede ser leída a partir de los estudios de Walter Benjamin en los que articula la serie conceptual que va desde el concepto de experiencia, pasando por el de memoria (voluntaria), ligado al de conciencia, y llegando hasta el de narración. Finalmente, propongo que la expresión "yo he visto un pájaro verde", leitmotive del cuento, constituye la síntesis emariana de la serie conceptual, es decir, la forma de elaborar el recuerdo de la experiencia narrable siguiendo una finalidad autocognoscitiva.
\end{abstract}

Palabras claves: Juan Emar, autoficción fantástica, modernidad narrativa, vanguardia, experiencia.

\begin{abstract}
:
In this research article I propose that Juan Emar's story "El pájaro verde" (The green bird) takes the form of fantastic self-fiction as theoretically stated about self-fiction by Vincent Colonna. Another proposal is that in this narration the self-fictional forms acquires its avant-garde features by being placed in correlation with a meta-discursiveness typical of narrative modernism. Such correlation can be read from the studies of Walter Benjamin where he articulates the conceptual series which cover from the concept of experience, going through the concept of memory (voluntarily), linked to that of conscience, until that of narration. I finally propose that the expression "I have seen a green bird", the leitmotive of the short story, constitutes the emarian synthesis of the conceptual series, that is, the way of elaborating the relatable experience with a self-cognitive purpose.
\end{abstract}

Key words: Juan Emar, fantastic self-fiction, narrative modernism, avant-garde, experience.

Recibido: 01 de octubre de 2021

Aceptado: 18 de noviembre de 2021 
Artículo. Cecilia Rubio Rubio. “'Yo he visto un pájaro verde’: experiencia, memoria y autoficción fantástica en la obra vanguardista de Juan Emar"

\section{Introducción}

En un trabajo temprano en la recepción de la obra narrativa de Juan Emar, Pedro Lastra ("Rescate de Juan Emar") planteaba que en esta se comienza con una demarcación de fronteras entre ficción y realidad, pero luego se termina proponiendo un canje y una fusión de ambos espacios, instaurando una zona dinámica de figuraciones de carácter suprarreal. Trabajos posteriores han sido más específicos en definir la índole de esos canjes y fusiones, como ocurre en el de Carlos Piña, titulado "El delirio biográfico de Juan Emar", donde se sostiene que Emar, sobre todo en su novela Umbral, manifiesta una marcada tendencia a la biografía y a la autobiografía. Otros estudiosos, como Soledad Traverso y Patricio Lizama, aunque no han sido explícitos, parecen tener una posición similar, por cuanto, para explicar alguna idea del escritor, han recurrido a su obra de ficción, citando, a modo de testimonio, algún pasaje de esta. Un caso más extremo, a mi entender, es el de Alejandro Canseco-Jerez, quien en su biografía de Juan Emar pasa del registro de hechos de la vida del escritor a citas de fragmentos de alguna de sus obras de ficción, como si pasar de la vida a la obra no requiriera mayor transición (cf. Juan Emar 106 y 107). Estas aproximaciones críticas dan cuenta de un aspecto de la obra emariana que resulta insoslayable si se pretende estudiarla y entenderla en su complejidad. Este aspecto se refiere a la puesta en funcionamiento de mecanismos de continuidad entre vida y obra, es decir, entre realidad y ficción, que condicionan y que estarían condicionados, a su vez, por la búsqueda de una nueva forma narrativa.

Por su parte, Pablo Brodsky ha mostrado la continuidad de vivencia a partir de ciertas simetrías entre la vida del escritor Juan Emar y la de su homónimo personajenarrador de "El pájaro verde":

el 12 de junio de 1934, el narrador de "El pájaro verde" escribe en el silencio de su biblioteca. En esa misma fecha, el autor de Diez estaba sentado en su escritorio, escribiendo un cuento llamado "El pájaro verde". De acuerdo a la historia del cuento, su narrador llegó a París en abril de 1924, dedicándose con varios amigos compatriotas, "noche a noche, a la más descomunal y alegre juerga" para regresar a Chile a fines de 1928 con un pájaro verde embalsamado en su maleta. El autor de Diez, por su parte, en abril de 1924 se encontraba en Chile (...) y a fines de 1928, estaba en París viviendo la crisis de su primer matrimonio. Los artículos y 
el libro tienen por autor a un tal Juan Emar ${ }^{1}$, quien es, asimismo, el narrador del cuento "El pájaro verde" (Emar, Diez 5).

En este trabajo afirmo que estos señalamientos de la crítica son acertados y encuentran su explicación en la modalidad narrativa que practicó Emar en su vida pública de escritor, que abarca tres novelas publicadas en 1935 y un libro de relatos, Diez, de 1937, al que pertenece el relato que más particularmente me ocupa.

Mi propuesta en este artículo es que podemos leer "El pájaro verde" de Juan Emar como un relato de la devaluación de la experiencia y de la narración, lo que necesariamente impulsa la búsqueda de una nueva o de una distinta manera de narrar, a la que puede denominarse autoficción fantástica, siguiendo la denominación que Vincent Colonna le da a una de las modalidades de la autoficción. Junto con ello, mi hipótesis interpretativa es que "El pájaro verde" y, en general, la obra emariana, está constituida por historias en que la inmediatez de la experiencia ha sido sustituida por frases u objetos convencionales, desprovistos de un significado evidente en la tradición. El desafío de Juan Emar a la forma narrativa puede estar contenido en esta pregunta: ¿Cómo escribir un relato que elude convertir la experiencia en narración?

\section{2. "El pájaro verde" como autoficción fantástica}

En "El pájaro verde" el autor y el narrador ostentan identidad onomástica, pues ambos reciben el nombre de Juan Emar. Como se sabe, cuando este rasgo se presenta en obras de ficción, permite inscribir dicha obra en la modalidad narrativa de la autoficción o ficcionalización de sí, que se aparta de la autobiografía por la ambigüedad de su pacto de lectura, que es tanto ficcional como referencial (cf. Manuel Alberca, “¿Existe...?”). La autoficcionalización de Emar es evidente en toda su obra publicada en vida, de allí que algunos críticos -muy pocos, en todo caso- lo hayan constatado. Selena Millares, por

\footnotetext{
${ }^{1}$ En este artículo, cuando me refiero a la "obra emariana" incluyo los textos recién nombrados y dejo fuera de mis afirmaciones los otros libros de ficción, de publicación póstuma, vale decir, las novelas Umbral (1996), Amor (2014) y Regreso (2016).
} 
Artículo. Cecilia Rubio Rubio. "'Yo he visto un pájaro verde': experiencia, memoria y autoficción fantástica en la obra vanguardista de Juan Emar"

ejemplo, en un trabajo de 2009, dice, al pasar: "Emar -autoficcionalizado como protagonista impenitente de sus textos- (...)" $(55)^{2}$.

A mi modo de ver, de los planteamientos sobre la autoficción el más adecuado para pensar en la obra emariana es el de Vincent Colonna ("L'autofiction"), quien define la autoficción así: “(...) una obra literaria en la cual un escritor se inventa una personalidad y una existencia, conservando su identidad real (su verdadero nombre)” (p. 30. Trad. mía ${ }^{3}$ ). Posteriormente agrega que en la autoficción tiene lugar la "adición paradojal de un protocolo nominal y de un protocolo modal ficcional" (op. cit. 38). Además, sostiene que la ya mencionada identidad onomástica entre autor y personaje, junto a indicaciones textuales y paratextuales que dan cuenta de su régimen ficcional, favorecen el rechazo de una lectura referencial. En todos estos sentidos, la autoficción es, en el decir de Colonna, no solo diferente de la novela autobiográfica, sino su "antítesis precisa" (op. cit. 9), pues mientras en esta el escritor utiliza como materia narrativa su existencia o un episodio de su vida, modificando por razones éticas o estéticas una gran cantidad de elementos, entre ellos, los nombres de los personajes, pero al mismo tiempo, invitando y promoviendo una lectura referencial que es correlativa a la actitud confesional del narrador, en la autoficción el autor se convierte a sí mismo en objeto de fabulación, inventando aventuras que se atribuye, y conservando su verdadero nombre, pero sin promover ni un tono confesional ni una lectura referencial, ni tampoco un valor figural o metafórico que induzca a una interpretación del texto como "confidencia(s) indirecta(s)" (op. cit. 10) ${ }^{4}$.

En el caso de la obra emariana, el protocolo nominal se cumple en virtud de uno de los recursos revisados por Colonna, al que llama homonimia por sustitución, que consiste en nombrar al personaje con un sustituto onomástico del autor al que este está vinculado pública o jurídicamente. De hecho, el nombre de Juan Emar, pseudónimo de Álvaro Yáñez, de alguna manera ha sustituido en el conocimiento del público el nombre civil.

\footnotetext{
${ }^{2}$ Cabe recordar que Millares al referirse a "El pájaro verde" lo relaciona con el "absurdo fantástico" (61), estética que ella entronca con el malditismo.

${ }^{3}$ Esta y todas las demás traducciones de los textos de Colonna son mías.

${ }^{4}$ Conozco la crítica que Julia Musitano hace a Colonna, pero ella no obsta para que los planteamientos del estudioso francés continúen siendo los más apropiados para abordar la obra de Emar en tanto autoficción. No podemos olvidar que la propuesta de Colonna tiene dos méritos indiscutibles que la diferencian de todas las demás: el de insertar la autoficción en una tradición y una historia literaria que viene de la Antigüedad y el de distinguir cuatro modalidades o formas literarias de la autoficción.
} 
Además, esta homonimia se completa con el uso de un narrador autodiegético, es decir, con la identidad entre protagonista y narrador. En términos más exactos, la autoficción emariana es fantástica, la que Colonna define como una variante en que

el escritor está en el centro del texto como en una autobiografía (es el héroe), pero transfigura su existencia y su identidad, en una historia irreal, indiferente a la verosimilitud. El doble proyectado deviene un personaje fuera de la norma, un puro héroe de ficción, del cual a nadie se le ocurriría sacar una imagen del autor. A diferencia de la postura biográfica, la fantástica no se limita a acomodar la existencia, sino que la inventa. La distancia entre la vida y el texto escrito es irreductible; la confusión, imposible; es la ficción de sí total (L'autofiction 75).

En el marco de esta definición y de sus implicancias, me interesa reflexionar sobre la obra de Juan Emar y dar respuesta a los problemas que la crítica ha planteado y que son insoslayables para leer esta obra desde una distinta concepción de lo literario, que incluye fronteras permeables, pasajes de contacto entre realidad y ficción, a través de mecanismos de continuidad entre vida y obra, todo lo cual es para mí signo inequívoco de que Emar estaba empeñado en la búsqueda de una forma narrativa nueva para la literatura de su tiempo.

No obstante lo recién dicho, la autoficción, tal como la concibe Colonna, no es una modalidad narrativa nueva, más bien, está ligada a los orígenes de la ficción narrativa, ya que es posible encontrarla en un autor como Luciano de Samosata, en quien Colonna encuentra el paradigma de las cuatro variantes de autoficción que él distingue. Esta remisión a Luciano no es ajena a los problemas histórico-narratológicos que ofrece la obra emariana. La serie de autores que establece Colonna, iniciada por Luciano y continuada por Rabelais y Cyrano de Bergerac es una serie donde lo cómico está asociado a lo fantástico, en un sentido amplio, y en la línea de lo cómico-serio, aspecto que para mí resulta altamente significativo en la filiación que se podría establecer entre la ficción emariana y la lucianesca. Recordemos que Bajtín, en Problemas de la poética de Dostoievski, se refiere al diálogo lucianesco para dar cuenta de la tradición de los géneros cómico-serios.

Al analizar el relato "El pájaro verde" desde el punto de vista de la autoficción, se puede observar que la actitud propia de esta forma narrativa, la ficcionalización de sí, que afecta al autor, es también verificable en el narrador personaje. Se trata de una actitud que 
Artículo. Cecilia Rubio Rubio. “'Yo he visto un pájaro verde’: experiencia, memoria y autoficción fantástica en la obra vanguardista de Juan Emar"

encuentra su razón de ser en la toma de conciencia de sí y de los procesos cognitivos involucrados en ella. Si a esto se añade la identidad de oficio entre autor y narradorpersonaje, se incorpora otra preocupación compartida que afecta ahora a la toma de conciencia de la acción escritural y de las resoluciones narrativas características del estado del problema narratológico en el momento de la vanguardia histórica. Esta preocupación se condice con la exhibición por parte del narrador de marcas de lo que Bajtín (Problemas...) llamó polémica oculta, es decir, una modalidad de dialogismo discursivo que consiste en tener en cuenta la virtual reacción del lector, de tal manera que esta va modalizando el discurso propio, como ocurre en el siguiente ejemplo del cuento que ahora analizo:

Y aquí comienza una nueva historia.

El mismo $1^{\circ}$ de enero de aquel año -es decir (acaso dato superfluo pero, en fin, viene a mi pluma) 81 años después de la llegada del doctor Guy de la Crotale a Tabatinga- (...) (Emar, Diez 20).

Como se observa, en este relato, el personaje es antes que nada un narrador que cuenta una historia, donde se imbrican tres unidades temáticas, la del loro, la del tío y la suya propia, y, como tal, es, sobre todo, un sujeto que escribe la historia y que se enfrenta a complicados problemas narratológicos. La primera muestra de ello se encuentra en la indicación metatextual que abre el relato: “Así deberíamos llamar este triste relato. Recurriremos a su origen, si es que hay algo en esta vida que tenga origen" (Diez 13). Nótese que en este comienzo Emar autor utiliza el procedimiento de aprovechar el título del relato, que es un elemento paratextual, como frase inicial. Como se observa, la consecuencia más relevante del uso de este recurso es que el autor promueve así otra continuidad, la que va desde su voz autoral, en tanto autor del paratexto, a la del narrador, personaje del texto. Otras referencias que comprometen la relación de este narrador con la historia y, por extensión, con lo narrable y con su propio estatuto como narrador, es la continua confesión de no conocer todos los detalles de la historia, así como el también continuo desplazamiento o diferimiento de la anécdota principal del relato. Veamos estos momentos: "De estos treinta y seis sabios, a mí, personalmente, sólo me interesa uno" (id.); "Del Doctor de la Crotale ignoro totalmente sus méritos (lo que, por cierto, no es negarlos) y de su sabiduría no tengo ni la menor noción (lo cual tampoco es negarla) (...). Todo lo cual no quita que el doctor Guy de la Crotale me interese en alto grado" (Diez 14); "Como 
este loro es el centro de cuanto voy a contar, daré sobre su vida y muerte algunos datos. Aquí van" (id.); y, por último, hay también referencias que atañen a la situación del narrador, las que revelan, como a contraluz, el lugar central que tiene para la historia que se narra la experiencia de este narrador-personaje: “y así es como el 16 de ese mes lanzó un suspiro y falleció en el mismo instante en que el más espantoso terremoto azotaba a la ciudad de Valparaíso y castigaba duramente a la ciudad de Santiago de Chile, donde hoy, 12 de junio de 1934, escribo yo en el silencio de mi biblioteca" (15).

Junto con ello, en parte de la obra narrativa emariana es observable el funcionamiento del tópico de la vida como espectáculo y como experimentación de sí. Dicho tópico, acaso más desarrollado en la novela Ayer, podemos verlo en la actitud del narrador-personaje de "El pájaro verde" frente al ataque del loro al tío José Pedro, de donde resulta que una de sus modulaciones es la de presentarse como una visión estética de la vida, que parece excluir un componente moral como conducta inmediata, y esta es otra manera de poner en práctica los postulados vanguardistas. En efecto, esta actitud estetizante del personaje se verifica en su admiración por la armonía de colores que se produce entre el cuerpo despedazado del tío y alguno de sus atuendos, o el color antes inimaginable de algún órgano puesto al descubierto a través de las heridas, actitud que va acompañada de la anulación de su capacidad de responder adecuadamente desde el punto de vista moral, lo que se expresa con el concepto de "deber", como se muestra en la siguiente cita:

(...) Era una ilusión nacida del deseo -harto legítimo, por lo demás- de que tanta belleza y gracia aumentase, siguiese, llegase a la vida propia y se elevase para recrear la vista con sus formas multiplicadas, el alma con su realización asombrosa.

Un tercer grito me volvió al camino de mi deber $(\ldots)$

Mi tío, después de esto, quedó hecho un espectáculo pasmoso.

(Diez 22-23).

De esta manera, toda experimentación del personaje emariano comienza en las vías sensorio-perceptuales para luego trasladarse hacia la experiencia cognitivo-especulativa. En los postulados poéticos vanguardistas, este recorrido constituye una vivencia estética. 
Artículo. Cecilia Rubio Rubio. "'Yo he visto un pájaro verde': experiencia, memoria y autoficción fantástica en la obra vanguardista de Juan Emar"

Para seguir articulando las tradiciones que se dan cita en el relato emariano, puedo señalar también dos asuntos referidos a la frase "Yo he visto un pájaro verde". Una es que se trataría de un tema popular que ha sido recogido con variantes en la letra y en el ritmo, pues admite el de tango, de zamba y de cueca, y ostentando el título común de "El cañaveral" ${ }^{\prime 5}$. La existencia real de esta composición musical vuelve a abrir la frontera entre ficción y realidad, a la vez que manifiesta una veta popular como una de las vertientes estéticas del relato, que entronca con Rabelais y los demás autores de autoficción fantástica ya mencionados. La otra cuestión es que la cuarteta completa que cita el narrador, esto es, "Yo he visto un pájaro verde / bañarse en agua de rosas / y en un vaso cristalino / un clavel que se deshoja" (17), puede inscribirse en la tradición hispánica del disparate que parodia las visiones medievales, tradición a la que se refiere José Manuel Pedrosa en su "Borges y la retórica del disparate: fuentes y correspondencias medievales, renacentistas y folclóricas de El Aleph", lo que nos permite vincular el "yo he visto" del tango citado por Emar con la serie de los "Vi" del narrador borgiano de "El Aleph", otro de los relatos que Colonna señala como autoficción fantástica, dada la homonimia entre autor y personaje que encontramos en el texto borgeano. Por cierto que la referencia al universo de lo lúdicocómico del disparate en el marco de lo popular, actualiza la relación del relato emariano con los géneros cómico-serios.

\section{Experiencia, memoria y narración. La modernidad narrativa en Juan Emar}

Para comenzar a delimitar el problema de investigación que me he propuesto, a saber, la relación entre la forma autoficcional en "El pájaro verde" y la modernidad narrativa, ${ }^{6}$ recurriré, a modo de sugestión, a dos casos a los que se refiere Walter

\footnotetext{
${ }^{5}$ En su artículo, Malva Marina Vásquez señala que los versos pertenecen a la zamba "El cañaveral", cuyo autor sería Andrés Charrazeta, quien se la adjudica como propia en 1916. Por mi parte, he encontrado datos en el sitio "Raíces musicales", en la entrada "Zambas y sus versiones-El cañaveral". Allí se consigna que en 1931 Andrés Chazarreta y su "orquesta nativa” graban La cañaveral, zamba, RCA Víctor 78 rpm. Se consigna también que las distintas versiones de las letras corresponderían a coplas de un cancionero popular. Ver Raicesmusicales.blogspot.com. El copyright del blog pertenece a Rubén Alcides Chamorro, quien se presenta como autor de los libros Zambas y algo más y Entre zambas y cuecas.

${ }^{6}$ Sobre la modernidad de la prosa emariana pueden darse varias referencias, por ejemplo, el artículo ya mencionado de Millares, y el más actual y mayormente dedicado al tema, de Julio Gutiérrez, “Ayer de Juan Emar: Impresiones patafísicas de la modernidad".
} 
Benjamin ${ }^{7}$. Uno, el del soldado que vuelve enmudecido de la guerra, en el ensayo "El narrador", de 1936, sirve a Benjamin -como puede desprenderse de otro ensayo suyo, "Sobre algunos temas en Baudelaire"- para ilustrar cómo la experiencia inmediata de las cosas puede parangonarse con el schock traumático, el que al impedir la toma de conciencia del hecho vivido, anula la capacidad de narrar la experiencia. Por eso, para Benjamin la decadencia de la narración y del narrador orales es el punto culminante de la crisis de la experiencia y esta decadencia coincidiría relativamente en el tiempo con el nacimiento de la novela.

El otro caso inicia el ensayo "Experiencia y pobreza" (1933) y es la parábola del anciano que en su lecho de muerte reúne a sus hijos para anunciarles la existencia de un tesoro enterrado en sus viñas, tesoro que resulta ser la transmisión de una experiencia y de una moraleja: el valor del trabajo por sobre el del oro. Benjamin invoca esta historia para ilustrar la importancia de la narración de parábolas en la época de su infancia, y, por contraste, lo que llama la devaluación de la experiencia y de la narración en el mundo moderno. Acompañan a esta parábola unas preguntas retóricas: “¿Acaso dicen hoy los moribundos palabras capaces de perdurar y de transmitirse como un anillo de generación en generación? ¿A quién le sirve hoy de ayuda un proverbio? ¿Y quién intentará habérselas con la juventud invocando su experiencia?” (95).

La forma autoficcional al menos en este relato es una de las herramientas con que Emar enfrenta el problema. En efecto, podemos visualizar al anciano moribundo que tiene una experiencia que comunicar y una lección consecuente que legar a los suyos, en el tío José Pedro frente al personaje Juan Emar, su sobrino, solo que, a diferencia del relato de Benjamin, en este, por un lado, el tío fracasa en su intento moralizante, y, por otro, el sobrino se ve impedido de rememorar y de reflexionar sobre su pasado, pues lo único visible que lo ata a él es un loro embalsamado y una frase. Sin embargo, esta constatación última no conduce a un dramatismo narrativo ni a la sensación de trauma, sino que más bien la devaluación de experiencia y narración es correlativa a una ganancia, a un aumento en el significado:

\footnotetext{
${ }^{7} \mathrm{Me}$ he encontrado recientemente con un recorrido por estos textos benjaminianos en Beatriz Sarlo, Tiempo pasado. Cultura de la memoria y giro subjetivo. Por cierto, aunque el recorrido pueda guardar alguna similitud con el mío, la estudiosa no tiene entre sus objetos de estudio la obra de Juan Emar.
} 
Artículo. Cecilia Rubio Rubio. “'Yo he visto un pájaro verde’: experiencia, memoria y autoficción fantástica en la obra vanguardista de Juan Emar"

- Yo he visto un pájaro verde...

Y así en todo. En realidad no había necesidad para entendernos, para expresar cuanto quisiéramos [,] para hundirnos en nuestros más sutiles pliegues del alma, no había necesidad, digo, de recurrir a ninguna otra frase. Y la vida, al ser expresada de este modo, con este acortamiento y con tanta compresión, tomaba para nosotros un cierto cariz peculiar y nos formaba una segunda vida paralela a la otra (...) (Emar, Diez 17-18).

Lo que quiero plantear aquí es que si la frase en cuestión tiene para Juan Emar el valor de compendio de toda una experiencia vital, como si fuera el proverbio o la parábola del mundo moderno, es porque, a diferencia de lo que contiene la parábola, la experiencia que encierra la frase no es comunicable o, al menos, no desea ser comunicada. Para comprender esto, puede venir en nuestra ayuda la distinción que propone Ortega y Gasset entre los vocablos "experiencia" (Erfahrung) y "vivencia" (Erlebnis). Según Jaime Cuenca, Cramer plantea el que puede ser el primer intento de definición del término "vivencia", realizado por W. T. Krug en su Diccionario enciclopédico de la última literatura e historia de la Filosofía (1838). Según esta definición, las vivencias constituyen el fundamento de la experiencia propia, si se sabe extraer de estas los resultados adecuados. Cuenca agrega:

En este sentido, como se ve, la vivencia (Erlebnis) aparece en una relación con la experiencia (Erfahrung) análoga a la que guardan las premisas implícitas de una operación intelectiva con su producto, o las fuentes diversas y confusas del aprendizaje con su formulación durable en la conciencia. Cuando este par de conceptos se oponen, la articulación sistemática y la cristalización en saberes o destrezas siempre cae del lado de la experiencia; la vivencia, en cambio, conserva cierto grado de inmediatez que no se deja reducir a significado (317). ${ }^{8}$

Por su parte, Blas Matamoro, refiriéndose a la novela Moriencia de Augusto Roa Bastos, explica la diferencia entre los dos términos de una manera muy significativa para lo que vengo desarrollando: "Tener vivencia no es lo mismo que tener experiencia, ya que esta es la parte comunicable de lo vivido, la exterior y social, la que puede codificarse con

\footnotetext{
${ }^{8}$ Resulta muy interesante seguir el recorrido histórico del término "vivencia" que realiza Cuenca en el mencionado artículo, dado que vincula el privilegio de la vivencia, en clara oposición a la experiencia, a los años 20 y a un impulso juvenil y antiburgués que, una década más tarde, adquirirá significados contrarios, al aliarse con el capitalismo y el valor económico ligado a las formas de ocio en una nueva cultura urbana.
} 
signos que los demás también poseen y comparten. En cambio, la vivencia es lo que permanece inmanente en el sujeto que ha experimentado algo, es la interioridad viva de la vida, si cabe la redundancia" (101).

Sin embargo, siguiendo el recorrido que hace Gadamer, Leonor Arfuch retoma la idea de que el término erlebnis entró a la literatura biográfica y, aludiendo a Dilthey, plantea que la vivencia adquiere estatuto epistemológico, pues llega a designar también "la unidad mínima de significado que se hace evidente a la conciencia, en reemplazo de la noción kantiana de 'sensación”" (35). Un momento más decisivo de la argumentación que yo retomo por su interés para el relato "El pájaro verde" ocurre cuando Arfuch cita a Gadamer, para quien la vivencia tiene un carácter trascendente, y la vivencia estética aparece como la "forma esencial" de la vivencia (36). Más adelante, Arfuch proporciona una síntesis de su planteamiento, en el que, como hemos visto, la vivencia no está desprovista de significado:

Esa cualidad fulgurante de la vivencia de convocar en un instante la totalidad, de ser unidad mínima y al mismo tiempo ir "más allá de sí misma" hacia la vida, en general; de iluminar, rescatar, atesorar, es quizá lo que hace de ella uno de los significantes que más insisten en el espacio biográfico (...). Impregnada de connotaciones de inmediatez, de libertad, de conexión con el "ser", con la verdad del "sí mismo", viene también a atestiguar de la profundidad del yo, a dar garantía de lo "propio" (66).

En otro de sus ensayos, "La experiencia" (1913), Benjamin atribuye a las personas mayores el concepto de la vida como acumulación de experiencias significativas, y a los jóvenes y a los niños, un concepto más cercano al juego de la experimentación y a la vivencia. En mi lectura del relato emariano, esta experimentación tiene como objeto momentos vividos como nuevos y únicos, que no llegan a ser acumulables y constitutivos de un saber gradualmente logrado. A través del recorrido por la memoria y por la narración en el proceso de construirse, esto es, en el entramado discursivo, el narrador relata sus trayectos del deseo, que son sobre todo trayectos fantásticos de su yo, que lo liberan tanto de la responsabilidad moral como de la adultez entendida como etapa superior de la vida. En un relato con este centro argumental, la fijación de la vivencia en una imagen o "frase guardián" (Emar, Diez) y la necesidad de narrarla pone en juego tanto el estatuto de la vivencia como el de la narración. 
Artículo. Cecilia Rubio Rubio. “'Yo he visto un pájaro verde’: experiencia, memoria y autoficción fantástica en la obra vanguardista de Juan Emar"

En resumen, lo que Benjamin llama la devaluación de la experiencia y, por consiguiente, de la narración, que afecta al sujeto moderno, es elaborada por Emar como una forma narrativa que crea su propio verosímil, en tanto forma distintiva del sujeto vanguardista. Y esto es así porque la llamada crisis del sujeto en la modernidad es también una crisis y una crítica de la experiencia, de la tradición y de la novela, de allí la práctica de una forma narrativa que se caracteriza por la ambigüedad de la construcción y del pacto de lectura. En última instancia, la frase síntesis, la frase que recubre semántica y expresivamente el conjunto de la vivencia no es solo la frase del tango, pues el loro introduce otra frase leitmotive e induce al personaje a hacer lo mismo. Recordemos el diálogo: “¿El señor Juan Emar, si me hace el favor?”, dice el loro; “Servidor de usted” (21), responde Juan Emar. A las tres frases puede aplicarse lo que el personaje dice de la primera de ellas, mostrando su carácter -podría decirse- figural: “(...) cuán infelices son todos aquellos que no han podido, siquiera una vez, reducir sus existencias a una sola frase que todo lo apriete, condense y, además, fructifica [sic]" $(18)^{9}$.

En definitiva, propongo que la expresión leitmotive "yo he visto un pájaro verde" constituye la síntesis emariana de la articulación entre los tres conceptos fundamentales del problema: experiencia, memoria y narración, es decir, constituye la forma de elaborar el recuerdo de la experienca narrable. El concepto de elaboración que uso aquí probablemente tenga resabios psicoanalíticos, pero la práctica se distanciaría de la elaboración analítica, en la medida en que la frase "yo he visto un pájaro verde" es expresión elaborada conceptualmente de la experiencia de "ver", tanto en la acepción que remite a la percepción sensorial como en la que remite a revelación. Como se sabe, por su sentido sagrado, esta revelación ocurre en un kairós, un tiempo marcado y fijado como el instante decisivo. De allí la pretensión del personaje de fijar el momento clave de la experiencia, como si pretendiera preparar el recuerdo significativo, es decir, proveer a la memoria del futuro de un punto en el que sostenerse para conocer el pasado, un punto en el que el presente se encuentra con el destino: "Esto fue el desatar, el cataclismo, la catástrofe. Esto fue el fin de su destino y el comienzo del total cambio del mío. Esto - alcancé a observarlo con la

\footnotetext{
${ }^{9}$ Debo hacer notar que la primera edición de Diez (Ercilla, 1937), dice en este momento: “(...) cuan infelices son todos aquellos que no han podido, siquiera una vez, reducir sus existencias todas a una sola frase que todo lo aprieta, condensa y, además, fructifica" (18).
} 
velocidad del rayo en mi reloj mural- aconteció a las 10 y 2 minutos y 48 segundos de aquel fatal 9 de febrero de 1931" (Diez 20-21).

Por todo lo señalado hasta aquí, y para continuar indagando en la modernidad narrativa emariana, interesa detenerse en la relación intertextual implícita que puede observarse entre "El pájaro verde" y la obra de Proust. Para ello, es necesario apoyarse en el hecho de que el escritor francés es aludido explícitamente en otros dos relatos emarianos: "El unicornio" y "El hotel Mac Quice". A mi entender, Proust constituye en la obra emariana un referente modélico que debe ser subvertido, si se quiere experimentar nuevas formas de narrar. Es decir que de la misma manera que la novela proustiana En busca del tiempo perdido es la manifestación de la crisis del relato memorialista tradicional, en el decir de Paul de Man (“¿Qué es lo moderno”?), la obra vanguardista representa la crisis de la novela de su tiempo. En el caso de Emar, el recurso a Proust parece estar motivado en la conciencia de esa crisis que, en plena vanguardia de los años treinta, es la marca de una imposibilidad, toda vez que muestra hasta qué punto Emar quiere diferenciarse de la técnica proustiana. Como contraparte, quizás lo monumental de la novela Umbral sea en Emar conciencia de otra imposibilidad: la de querer narrar la historia de una vida y no parecerse a Proust. Porque si, por un lado, Proust es para Emar una suerte de antimodelo, de la misma manera que lo es Shakespeare en "El unicornio", y ambos escritores lo son por su morosidad en la meditación, el escritor francés se nos presenta también cercano a la idea emariana de la experiencia. En efecto, Benjamin, refiriéndose a la relación que Proust establece con el texto de Bergson, Materia y memoria, señala que, para el escritor, el problema con la memoria voluntaria es que esta no retiene nada del pasado, pues este "se encuentra 'fuera de su dominio de la inteligencia y de su alcance, en algún objeto material [...] que no sospechamos. Del azar depende que encontremos o no ese objeto antes de morir"” (Benjamin, "Sobre algunos temas" 272). A esta cita de Proust, Benjamin acota: "Según Proust, se trata por tanto de cosa del azar que cada uno pueda obtener así una imagen de sí mismo, que pueda adueñarse de su experiencia. Aunque de ningún modo resulta evidente que en tal asunto se dependa del azar" (272). Si esto es así, añade Benjamin, es porque han disminuido las probabilidades de incorporar a la experiencia las aspiraciones de los seres humanos, como efecto de la pérdida de la narración oral, el predominio de la información entregada por los medios de prensa y el relevo de esta por la 
Artículo. Cecilia Rubio Rubio. “'Yo he visto un pájaro verde’: experiencia, memoria y autoficción fantástica en la obra vanguardista de Juan Emar"

sensación, es decir, periodismo y sensacionalismo serían los nuevos medios por donde circula la cada vez más atrofiada experiencia de los sujetos, que ha perdido su contacto con la sabiduría de la que se participaba a través de la narración oral y los proverbios. Para demostrar cómo Proust está implicado en este proceso, Benjamin lanza un corolario muy significativo del estado de la cuestión: "La voluminosa obra de Proust da una idea de todas las disposiciones que fueron necesarias para restaurar en la actualidad la figura del narrador" (273).

De manera similar, Paul de Man rechaza la idea de que Proust sea un psicologista de la novela, y sostiene que tanto su narrativa como la de Joyce "nacen del desesperado esfuerzo por crear un diálogo que se ha vuelto cada vez más difícil (y aquí la palabra “diálogo" debe entenderse en su sentido más amplio que abarca todos los aspectos del lenguaje intersubjetivo, no solo el diálogo realista)" (147).

Resulta claro, a partir de estos comentarios, que Proust es la clave de un momento de la historia del relato en la época contemporánea y cómo este momento crítico lo llevó a plasmar una nueva forma narrativa. Así lo señala también Carlos García-Bedoya, para quien la novela de Proust está en la frontera de dos siglos, ya que, pese a su esteticismo decimonónico, "cuestionaba la primacía de lo narrativo" (221) otorgando "peso similar a los componentes narrativos, descriptivos y reflexivos" (id.), por lo cual subvirtió las tradicionales delimitaciones de los géneros y se acercó de este modo a las corrientes literarias propias del siglo XX.

Además de esto, hay que agregar otro nivel de realidad que se produce y conjuga en los relatos emarianos, me refiero al universo que es aludido a través de la metalepsis, se trata de un mundo exterior a la diégesis que está contaminado por la visión ficcional que se impone en el relato, a la vez que se llena de contenido intertextual y metanarrativo. Así, en el cuento "Maldito gato", luego de que el narrador ha descrito un cuadro que hay en su casa -cuadro de la artista "Gabriela Emar" (Diez 59), es decir, quien en nuestro mundo real era por allá por el año de creación del cuento -1937- la pintora Gabriela Rivadeneira, esposa del escritor, y que toma en la ficción emariana el apellido seudónimo del autor-, comenta para el lector no tan virtual: "No sé si esto dé idea de dicho cuadro. En fin, supongo que ha de estar aún en casa. Quienquiera, que vaya y lo mire" (60). Digo lector no tan virtual, porque este es interpelado desde la ficción como lector real contemporáneo del autor real, 
en un enunciado que se entrega de persona a persona, despojando el relato de toda su ficcionalidad. Como se observa, el mundo real era para Emar perfectamente literaturizable mientras el mundo literario era también cabalmente real.

Otro caso interesante respecto de la noción de realidad literaria en Emar y la vanguardia es el que atañe a la intertextualidad restringida, pues este recurso promueve la creencia de que vida y ficción literaria se retroalimentan en un flujo constante, en la medida en que reconocemos en la alusión a una obra del mismo autor el trayecto directo de una obra a otra, lo que nos permite relacionarnos con este narrador personaje identificándolo con el escritor, autor, en principio, de las dos obras concernidas. Como se observa, este flujo entre realidades y niveles de realidades que se produce por la identidad de los personajes, pero también por aspectos de la diégesis, afecta de la misma manera la identidad del lector real, quien se reconoce como lector de ambas obras, como si fuera también él quien deambula por una realidad y otra, como si también fuera él personaje de la diégesis. Veamos cómo ocurre en el relato "El unicornio". Dice el narrador: "Esta meditación cobijada me recordó el consejo que el mismo personaje [Desiderio Longotoma] me dio el $1^{\circ}$ de octubre del año pasado bajo el árbol de coral" (Diez 81). Sin duda, solo el lector avezado en la obra emariana puede reconocer sin dificultad la referencia, puesto que el árbol de coral nace a la vida literaria en la novela $U n$ año, publicada por el mismo escritor en 1935. Esta novela, que parodia un diario de vida, articula la historia de vida del narrador a través de capítulos titulados según el primer día de cada mes del año. Es justamente en el capítulo "Octubre $1^{\circ}$ " en el que se forma el árbol de coral, bajo el cual se ubica Desiderio Longotoma, quien, entre otras conversaciones sostenidas con el narrador protagonista, le da, efectivamente, un consejo sobre la práctica de la meditación bajo el árbol (cf. Un año 90-91), lo que el protagonista del cuento llama "meditación cobijada". Todo esto, para mí, está en la línea del diálogo que la obra emariana sostiene con la novela de Proust, específicamente, con la parte denominada "A la sombra de las muchachas en flor". 
Artículo. Cecilia Rubio Rubio. “'Yo he visto un pájaro verde’: experiencia, memoria y autoficción fantástica en la obra vanguardista de Juan Emar"

\section{Conclusiones}

En este artículo he propuesto que la obra de Emar y en particular el relato "El pájaro verde" forma parte de una poética general emariana de autoficción fantástica. Con ello he querido contribuir a precisar en qué consiste la excepcionalidad de Emar en tanto escritor de narrativa vanguardista. Me ha interesado sobre todo mostrar que la práctica autoficcional no debe confundirse con la práctica autobiográfica, pues lo que distancia a una de la otra es más que una cuestión de géneros discursivos, ya que la autoficción se niega a ser bio, es decir, a entregarse como "vida de" con una intención propiamente mimética.

En efecto, la autoficción designa el devenir ficción del yo poniendo de manifiesto que su contenido es sobre todo el trayecto que este yo recorre, pues nunca llegará a ser una vida completa, lista para ser contada, como si hubiera que reducir la historia de vida a un cúmulo de experiencias de las que se obtiene una verdad. Por el contrario, específicamente, en la autoficción fantástica no hay espacio de separación entre el yo y su ficción, ya que en ese recorrido, el yo toma el camino del rehacerse por medio de la escritura, que deviene tránsito hacia lo otro, hacia la fantasía y los mundos posibles ficticios. El proyecto literario emariano es totalmente congruente con la autoficción fantástica, modo escritural que resulta la forma literaria perfecta para albergar un yo en continua transformación, un yo que no quiere afincarse en la experiencia de un saber acumulado, sino en la evanescente vivencia, alojada en el presente.

De alguna manera, la narración vanguardista emariana toma la forma de un relato posible de la cotidianidad, sin más pasado ni tradición a la que aferrarse para construirse un rostro novelesco, que la de la vivencia inmediata. Es la imagen de una modernidad precaria y azarosa. La frase "Yo he visto un pájaro verde" constituye una suerte de emblema de la búsqueda de un sentido de la vivencia convertida en experiencia, y responde ambiguamente -como lo hace toda la obra emariana- a la idea de Proust de que depende del azar que podamos obtener un retrato de la experiencia. El personaje autoficcional emariano se debate por encontrar un significado que lo sostenga, y que se encuentra entre el azar, el deber y el destino, al mismo tiempo que busca una forma narrativa que le permita escriturar ese trayecto. Al mismo tiempo, y desde la perspectiva autorial, el encuentro y práctica de la autoficcción fantástica como forma narrativa, junto con alejarlo de los referentes habituales 
en la literatura chilena, le da un lugar en otras tradiciones literarias cuya incidencia real es necesario estudiar a fondo, la de los géneros cómico-serios.

\section{REFERENCIAS}

Alberca, Manuel. ¿Existe la autoficción hispanoamericana? Cuadernos del CILHA, núm. 78, 2005-2006, pp. 115- 127.

---. El pacto ambiguo: De la novela autobiográfica a la autoficción. Editorial Biblioteca Nueva, 2007.

Arfuch, Leonor. El espacio biográfico. Dilemas de la subjetividad contemporánea. Fondo de Cultura Económica, 2010.

Bajtín, Mijail. Problemas de la poética de Dostoievski, traducción directa del ruso e índices de Tatiana Bubnova; introducción, bibliografía, cronología y revisión de Tatiana Bubnova y Jorge Alcázar. Fondo de Cultura Económica, $3^{\mathrm{a}}$ ed., 2012.

Benjamin, Walter. "Experiencia". Metafísica de la juventud, introducción de Ana Lucas. Paidós I.C.E. / U.A.B., 1993, pp. 93-97.

---. "Experiencia y pobreza (1933)”. Iluminaciones, edición y prólogo de Jordi Ibáñez Fanés; traducciones de Jesús Aguirre y Roberto Blatt. Taurus, 2018, pp. 95-100.

---. “El narrador. Consideraciones sobre la obra de Nicolái Léskov (1936)”. Iluminaciones, edición y prólogo de Jordi Ibáñez Fanés; traducciones de Jesús Aguirre y Roberto Blatt. Taurus, 2018, pp. 225-251.

---. “Sobre algunos temas en Baudelaire (1939)”. Iluminaciones, edición y prólogo de Jordi Ibáñez Fanés; traducciones de Jesús Aguirre y Roberto Blatt. Taurus, 2018, pp. 269306.

Brodsky, Pablo. "Prólogo". Diez. Tajamar, 2006, pp. 5-11.

Canseco-Jerez, Alejandro. Juan Emar: estudio. Documentas, 1989.

Canseco-Jerez, Alejandro, editor. Juan Emar. Cartas a Pépèche, estudio bibliográfico y cuidado del texto de Soledad Traverso. Artextos, 2007.

Colonna, Vincent. L'autofiction (essai sur la fictionalisation de soi en Littérature). 1989. École des Hautes Études en Sciences Sociales, Théses de doctorat. Versión electrónica de 2004, disponible en http://tel.archivesouvertes.fr/docs/00/04/70/04/PDF/te100006609.pdf

---. Autofiction \& autres mithomanies littéraires. Éditions Tristram, 2004.

Cuenca, Jaime. "Génesis de la comprensión experiencial del ocio en la modernidad tardía: transformaciones del concepto de vivencia”. ARBOR, núm. 754, marzo-abril 2012, pp. 315-325. doi: 10.3989/arbor.2012.754n2005

De Man, Paul. "¿Qué es lo moderno? (1965)". Escritos críticos (1953-1978), edición e introducción de Lindsay Waters; traducción de Javier Yagüe. Visor, 1996, pp. 231238.

Emar, Juan. Un año. Editorial Sudamericana, 1996.

---. Umbral. 5 vols. Biblioteca Nacional, 1996.

---. Ayer. Lom, 1998.

---. Diez. Tajamar, 2006.

---. Amor. La Pollera, 2014. 
Artículo. Cecilia Rubio Rubio. "'Yo he visto un pájaro verde': experiencia, memoria y autoficción fantástica en la obra vanguardista de Juan Emar"

---. Regreso. La Pollera, 2016.

García-Bedoya, Carlos. "Proust y la modernidad narrativa". Letras, núm. 120, 2013, pp. 211-223.

Gutiérrez, Julio. "Ayer de Juan Emar: Impresiones patafísicas de la modernidad”. Anales de Literatura Chilena, núm. 27, 2017, pp. 69-82.

Lastra, Pedro. "Rescate de Juan Emar". Revista de Crítica Literaria Latinoamericana, núm. 5, 1977, pp. 67-73.

Lizama, Patricio. "Juan Emar y La Nación de Santiago de Chile en París (1926-1927)", Anales de Literatura Chilena, núm. 2, 2001, pp. 191-206.

Matamoro, Blas. "Una vida y dos muertes". Cuadernos Hispanoamericanos (Homenaje a Roa Bastos), núm. 493-494, 1991, pp. 101-105.

Millares, Selena. "Una poética del absurdo visionario: Juan Emar". Anales de Literatura Chilena, núm. 12, 2009, pp. 53-64.

Musitano, Julia. "La autoficción: una aproximación teórica. Entre la retórica de la memoria y la escritura de recuerdos". Acta literaria, núm. 52, 2016, pp. 103-123.

Pedrosa, José Manuel. "Borges y la retórica del disparate: fuentes y correspondencias medievales, renacentistas y folclóricas de El Aleph". Dicenda, Cuadernos de Filología Hispánica, núm. 14, 1996, pp. 215-233.

Piña, Carlos. "El delirio biográfico de Juan Emar". Taller de Letras, núm. 26, 1998, pp. 143-147.

Traverso, Soledad. Juan Emar: la angustia de vivir con el dedo de Dios en la nuca. Ril, 1999.

Vásquez, Malva Marina. "Escucha Barroca y Vanguardia Latinoamericana en El pájaro verde de Juan Emar". Hispanófila, núm. 176, 2016, pp. 175-190. 